\title{
A new species of the micro snail genus Heleobia (Caenogastropoda, Cochliopidae) from Bahia, Brazil
}

\author{
Luiz Ricardo L. Simone ${ }^{1,2}$ \& George Vita de Oliveira ${ }^{1,3}$
}

\author{
1 Universidade de São Paulo (USP), Museu de Zoologia (MZUSP). São Paulo, SP, Brasil. \\ 2 ORCID: http://orcid.org/0000-0002-1397-9823. E-mail: Irsimone@usp.br \\ 3 ORCID: http://orcid.org/0000-0003-2527-1950.E-mail: georgevita@usp.br
}

\begin{abstract}
The prey of a recent described characid fish, so far endemic of the small lake Pratinha (Iraquara, Bahia, Brazil), a small $(\sim 2.5 \mathrm{~mm}$ ) lentic gastropod, revealed to be a new (possible endemic) species. It is herein formally described as Heleobia brucutu sp. nov. The description includes anatomical features, revealing interesting idiosyncrasies such as egg laying attached to shell, and penis lacking glands, but with terminal papilla. The new species appears to be endemic of that small lake as much as its fish predator. As the species is now formally described and named, protective efforts must be implemented.
\end{abstract}

Keywords. Mollusca; Anatomy; Morphology; Taxonomy.

\section{INTRODUCTION}

Astyanax brucutu Zanata, Lima, Dario \& Gerhard, 2017, is a characid fish recently described, endemic of a small lake of the Pratinha stream, Paraguaçu Basin, Bahia, Brazil. It is distinct in being the single species of the genus having jaws modified to smash small gastropods. This paper deals with the gastropod species that sustains that fish species. The analysis of the gastropod shell and anatomy revealed it belongs to a new species, formally described herein, possibly, as much its predator, also endemic from that lake.

The new snail belongs to the genus Heleobia Stimpson, 1865 (type species Paludina culminea d'Orbigny, 1838 OD) (Hershler \& Thompson, 1992; Kabat \& Hershler, 1993; Koch et al., 2015), subfamily Semisalsinae, family Cochliopidae, superfamily Truncatelloidea (Koch et al., 2015). The genus has $\sim 40$ species and is widespread in South America, being more specious in the Andean region (Hershler \& Thompson, 1992); in Brazil, 14 species are known (Simone, 2006a, as Littoridina). The species of Heleobia has usually a high level of endemicity (Silva \& Veitenheimer, 2004; Simone, 2006a; Simone \& Rolán, 2021).

As much as its predator, the new Heleobia is described already with the suggestion of it being considered endangered, based on its endemicity and environmental restriction (see discussion).

\section{MATERIAL AND METHODS}

The collection methodology is reported elsewhere (Lima \& Gerhard, 2001; Zanata et al., 2017), including gastropods samples from both inside the fish stomach and collected on the sediment. The samples consist of specimens fixed in 70\% $\mathrm{EtOH}$, extracted from their shells by means of shell crush and posteriorly dissected by standard techniques under stereomicroscope (Simone, 2011). Shell was also examined in SEM, in the Laboratório de Microscopia Eletrônica, Museu de Zoologia da Universidade de São Paulo (MZSP), institution were the samples are deposited.

In the figures, the following abbreviations are used: ag, albumen gland; an, anus; au, auricle; bg, buccal ganglion; ce, cerebral ganglion; cg, capsule gland; $\mathbf{c m}$, columellar muscle; $\mathbf{c v}$, ctenidial vein; $\mathbf{d d}$, duct to digestive gland; $\mathbf{d g}$, digestive gland; es, esophagus; ey, eye; fe, fecal pellet; fp, female pore; fs, foot sole; $\mathbf{f t}$, foot; $\mathbf{g d}$, genital inner tube; gi, gill; gp, pedal ganglion; in, intestine; jw, jaw; ki, kidney; m2-m10, extrinsic and intrinsic odontophore muscles; $\mathbf{m b}$, mantle border; $\mathbf{m j}$, jaw and peribuccal muscles; mo, mouth; ne, nephrostome; oc, odontophore cartilage; od, odontophore; of, osphradial satellite fold; op, operculum; os, osphradium; ot, oral tube; pc, pericardium; pd, penis duct; $\mathbf{p e}$, penis; $\mathbf{p g}$, anterior furrow of pedal gland; pi, penis papilla; pp, pleural ganglion; pt, prostate; rn, radular nucleus; rs, radular 
sac; rt, rectum; sn, snout; sr, seminal receptacle; ss, style sac; st, stomach; su, subesophageal ganglion; sv seminal vesicle; sy, statocyst; ta, terminal genital atrium; te, cephalic tentacle; ts, testis; vd, vas deferens; ve, ventricle; vo, visceral oviduct.

\section{RESULTS}

\section{Systematics}

\section{Heleobia brucutu new species}

(Figs. 1-26)

http://zoobank.org/B8DB24F5-FBA3-4062-89E7-A31BB559F087

\section{Types: Holotype MZSP 151288 (Figs. 1-3).}

Paratypes from type locality: MZSP 151289, 50 specimens, MZSP 152202, 35 specimens, MZSP 152203, 1 metalized shell (Figs. 13-15).

Type locality: Brazil, Bahia, Iraquara, Lagoa da Pratinha, Pratinha River, Paraguaçu River basin. Elevation 642 m, $12^{\circ} 21^{\prime} 10^{\prime \prime} \mathrm{S}, 4^{\circ} 32^{\prime} 24^{\prime \prime} \mathrm{W}$ [Angela Maria Zanata, George Vita \& Rafael Burger col. 29/xi/2016) (Fig. 2).

Etymology: The specific name is in apposition and refers to the epithet of the better-known fish predator, Astyanax brucutu.

Diagnosis: Shell minute (up to $2.5 \mathrm{~mm}$ ), slightly turriform, suture well-marked, whorls profile slightly rounded. Jaws small, reduced. Insertion of visceral vas deferens close to origin of pallial vas deferens. Penis lacking glands, with terminal papilla and lateral-terminal projection. Pallial oviduct with elongated bursa copulatrix and seminal receptacle originated close from each other. Egg capsules attached externally to adult shells.

\section{Description}

Shell: (Figs. 1-6, 9-16) size 2 mm; elongate, slightly conic-turriform, $\sim 65 \%$ longer than wide, weakly umbilicate; whorls blandly convex, rounded, suture shallow but well-marked (Figs. 13-15); adult 5-6 whorls. Sculpture absent except for weak growth lines (Figs. 2, 5, 14). Color pale beige, opaque (Fig. 1-6, 9-11), periostracum thin, mostly eroded in older regions (Figs. 3, 6, 9). Protoconch (Fig. 9, 14, 17) of $\sim 240 \mu \mathrm{m}$, with $\sim 1.5$ smooth whorls; color white. Teleoconch of $\sim 4$ whorls. Spire angle $\sim 55-65^{\circ}$, with blunt apex. Aperture oval, peristome continuous, weakly attached to penultimate whorl (Figs. 1, 4, 9, 10, 13, 16); no callus; $\sim 40-50 \%$ of total shell length, $\sim 60$ of shell width; profile almost orthocline, $\sim 15^{\circ}$ with longitudinal shell axis (Fig. 4, 13); inner lip smoothly concave; outer lip and interior third on inner lip performing continuous semi-circle (Figs. 9, 10, 16), relatively thick; anal region angled in $~ 85$; incurrent region widely rounded. Umbilicus very narrow, mostly covered by middle region of peristome inner lip.
Head-foot (Figs. 19-20, 24): Relatively short, relatively narrow; mostly unpigmented, with pale brown spots in lateral edge of foot and snout. Mesopodium sole thick, short, slightly wider than long ( $\mathrm{fs})$. Anterior furrow of pedal glands $(\mathrm{pg})$ deep, restricted to anterior edge. Opercular pad elliptic, terminal, occupying most of posterior foot dorsal surface. Head bulbous, with $\sim 80 \%$ of food width; pair of cephalic tentacles (te) simple, thick, with half foot length. Eye (ey) large, at outer tentacles base; occupying more than half width of tentacles base. Snout as long as tentacles; double tentacles width (sn); anterior slightly bilobed. Columellar muscle thick, $3 / 4$ whorl, simply curving to right $(\mathrm{cm})$.

Operculum (Figs. 7-8): Corneous, thin, translucent, pale yellow-beige, flexible, paucispiral. Outline semi-circular, $\sim 1.2$ longer than wide. Nucleus subcentral. Occupying entire shell aperture (Fig. 1).

Mantle organs (Figs. 23, 26): Pallial cavity $\sim 1$ whorl in length. Mantle edge simple, weakly thick wide; unpigmented. Osphradium (os) short, elliptical, simple; length $\sim 10 \%$ pallial cavity length; 3-times longer than wide; located in anterior-left corner of cavity, close to gill and from mantle border; osphradial satellite fold (of) present, with $\sim$ half of osphradium width. Gill (gi) elongated, narrow, with $\sim 70 \%$ of pallial cavity length and $1 / 6$ of cavity width; anterior end blunt, posterior from mantle edge; width relatively uniform along length; filaments ending at anterior edge of pericardium. Gill filaments tall, narrow, distal tip blunt (gi); relatively few filaments $(\sim 12)$. Between gill and rectum wide distance equivalent to $1 / 4$ of pallial cavity width. Hypobranchial gland inconspicuous. Rectum narrow, with small posterior curve (concavity right), up to $1 / 8$ of pallial cavity width; bearing aligned series of transversely disposed, elliptical, white fecal pellets (fe), easily seen by translucence; rectum slightly displaced from right mantle cavity edge. Anus simple, shortly siphoned, located short distance from mantle border at $\sim 10 \%$ of cavity length. Genital ducts running along right-posterior edge, relatively massive, described below.

Visceral mass (Fig. 23): Length 3 whorls. Most structures color pale beige to white, local mantle dark pigmented in superior half. Reno-pericardial (ki, pc) organs as anterior structure. Stomach (st) compressing anteriorly small reno-pericardial structures; stomach of $\sim 0.5$ whorl, with almost entire adjacent whorl width. Digestive gland light beige, of $\sim 2.5$ whorls, mostly posterior to stomach. Gonad (ts) running along columellar surface of each whorl when mature. Other genital and digestive details below.

Circulatory and excretory systems (Fig. 23): Pericardium rounded, located longitudinally between stomach and left-posterior corner of pallial cavity $(p c)$, volume $\sim 1 / 20$ of that of visceral mass; auricle (au) anterior, small, just posterior to posterior end of ctenidial vein (cv); ventricle (ve) posterior, simple. Kidney (ki) minute, weakly smaller than pericardium, located in right side of pallial cavity posterior end; inner tissue scanty, mostly hollow, white. 
Nephrostome (ne) small, transverse, located close middle distance between pericardium and adjacent rectum.

Digestive system (Figs. 21-23): Mouth (mo) in ventral surface of snout. Buccal mass occupying entire snout inner surface and $\sim 1 / 4$ of haemocoelic volume. Oral tube (ot) conic, wide, with $\sim 1 / 4$ buccal mass length. Pair of jaw plates (Figs. 21-22: jw) small, laterally located; each one as long as wide, obliquely disposed, very thin, translucent. Pair of buccal ganglia relatively large (bg). Odontophore spherical, with half of buccal mass volume.

Odontophore muscular arrangement (Figs. 21, 22): m2, pair of small protractor muscles of buccal mass, originating in ventral surface of haemocoel, in posterior level of odontophore, running dorsal-posteriorly, inserting in latero-posterior surface of odontophore; $\mathbf{m 4}$ : pair of main dorsal tensor muscles of radula, surrounding externally both cartilages, relatively narrow; $\mathbf{m 5}$, pair of auxiliary dorsal tensor muscles of radula, originating between $\mathrm{m} 4$ and cartilages in posterior-median region, running medially and anteriorly, inserting in middle region of radular sac; $\mathbf{m 6}$, horizontal muscle, connecting ventral edge of both cartilages, along 75\% their length, half cartilages width; $\mathbf{~ m j}$, air of jaw and peribuccal muscles, originating in outer-lateral region of cartilages, running anteriorly splaying in oral tube and having main lateral band (Fig. 22) up to lateral region of mouth. Radular sac $\sim$ twice longer than odontophore (Fig. 21: rs); radular nucleus (rn) weakly widening.

Radula (Fig. 18): Typical for the family; rachidian tooth occupying $\sim 20 \%$ of radular ribbon width, double width than high, cutting edge concave, strongly curved, central cusp relatively large, 4 pairs of secondary cusps gradually smaller towards lateral; no basal cusps except for pair of lateral thickening, possessing rounded nodule in median side as large as first secondary cusp; lateral tooth with main region triangular, with $\sim$ double rachidian height, $60 \%$ its width; 4 cusps similar to central cusp of rachidian, similar-sized; inner and outer lateral tooth similar shaped with each other, being outer tooth $~ 30 \%$ narrower than inner marginal tooth, same length as lateral tooth and $\sim 20 \%$ narrower, general form as a rod curved inwards at tip, tip flattened, bearing 8 inner small terminal cusps of similar size from each other; each cusp small, sharp pointed. Salivary gland absent. Esophagus simple, zigzagging along haemocoel (Fig. 21: es), slightly broader in its middle region, lacking apparent glandular areas. Stomach dimensions and position above described (visceral mass); possessing main gastric chamber posterior (Fig. 23: st), posterior surface rounded. Style sac narrow (Fig. 23: ss), with $~ 3 / 4$ remaining gastric width, and double its length. Esophagus (es) inserting in posterior-left region of stomach, very narrow; intestinal (in) origin on left side of posterior level of style sac; duct to digestive gland (dd) almost as broad as esophagus, located in middle of posterior-ventral stomach region, running towards posterior. Intestine (in) slightly narrower than esophagus; running surrounding ventrally style sac anterior surface up to right posterior end of style sac, in this region fecal pellets appearing, subtly curving towards anterior and dorsal running to pallial cavity (Fig. 23: in). Rectum and anus above described (pallial cavity).

Genital system: Male (Figs. 23-24): Seminal vesicle (sv) very narrow, highly convolute, located in columellar region of visceral mass ventral-posterior to stomach, color pale grey-iridescent; narrow, straight portion of vas deferens, $\sim 1 / 2$ whorl in length, inserting in prostate subterminally (Fig. 23: sv), just posterior-left level of prostate. Prostate with $\sim 1 / 5$ pallial cavity width, slightly dorso-ventrally flattened, white (Fig. 23: pt). Pallial vas deferens originating from prostate ventral-middle region, opposite to visceral vas deferens insertion (Fig. 23: vd); after short distance penetrating in floor of pallial cavity up to of penis base, running immersed in integument (Figs. 20, 24: vd). Penis (Figs. 19, 20, 24: pe), simple, curved, elongated ( $1 / 4$ of pallial cavity) base broad, gradually tapering up to bluntly pointed tip. Penis duct seen by translucence, running straightly along central penial region, up to penis distal tip (Fig. 24: pd); penial terminal papilla (pi) with penial aperture distal, simple, small. Female (Fig. 26): Ovary size and localization similar to those of testicle. Visceral oviduct very narrow, running along middle level of columellar surface of visceral mass $~ 1$ whorl (vo). Visceral oviduct inserting at base of seminal receptacle (vo). Seminal receptacle (sr) small ( ${ }^{1} / 10$ of entire pallial oviduct), balloon-like, inner lumen pigmented dark, arched. Internal, broad duct originating in receptacle base (gd), sigmoid, running immersed in albumen gland up to opposed side in right-posterior region. Albumen (ag) and capsule gland (cg) as continuation from each other, white, without clear separation. Capsule gland tapering gradually towards anterior up to terminal atrium. Terminal atrium (ta) of $\sim 1 / 6$ of pallial oviduct, conic, walls weakly thick. Female pore (fp) sessile, papilla-like, aperture longitudinal, turned ventrally, located close to and slightly posterior to anus (an).

Central nervous system (Fig. 25): Nerve ring located just posterior to buccal mass, with pedal ganglia weakly more anterior than remaining ganglia. Each cerebral ganglion (ce) oval, with size equivalent to esophageal section; cerebral commissure narrow, half-length of each ganglion. Pleural ganglia (pp) with $\sim 1 / 5$ size of cerebral ganglia, located just ventral to them fused with cerebral ganglia by constriction. Each pedal ganglion (gp) as large as cerebral ganglion, somewhat spherical; pedal commissure narrow, minute. Cerebro-pedal and pleuro-pedal connectives narrow, about as long as pedal ganglia. Subesophageal ganglion (su) almost as large as pleural ganglion, located short distance from right pleural ganglion. Pair of statocysts (sy) located in ventro-anterior side of pedal ganglia.

Measurements (length and width in $\mathrm{mm}$ ): Holotype 2.7 by 1.6 (Figs. 13-15). Paratypes MZSP 151289 (dissected specimens) \#1 (Figs. 1-3): 2.6 by 1.4; \#2 (Figs. 4-6): 2.5 by $1.4 ; \# 3$ (Fig. 9 ): 2.0 by $1.2 ; 10-11$, \#4, frontal and right views (L $2.4 \mathrm{~mm}$ ); \#4 (Figs. 10-11): 2.4 by 1.4 . 


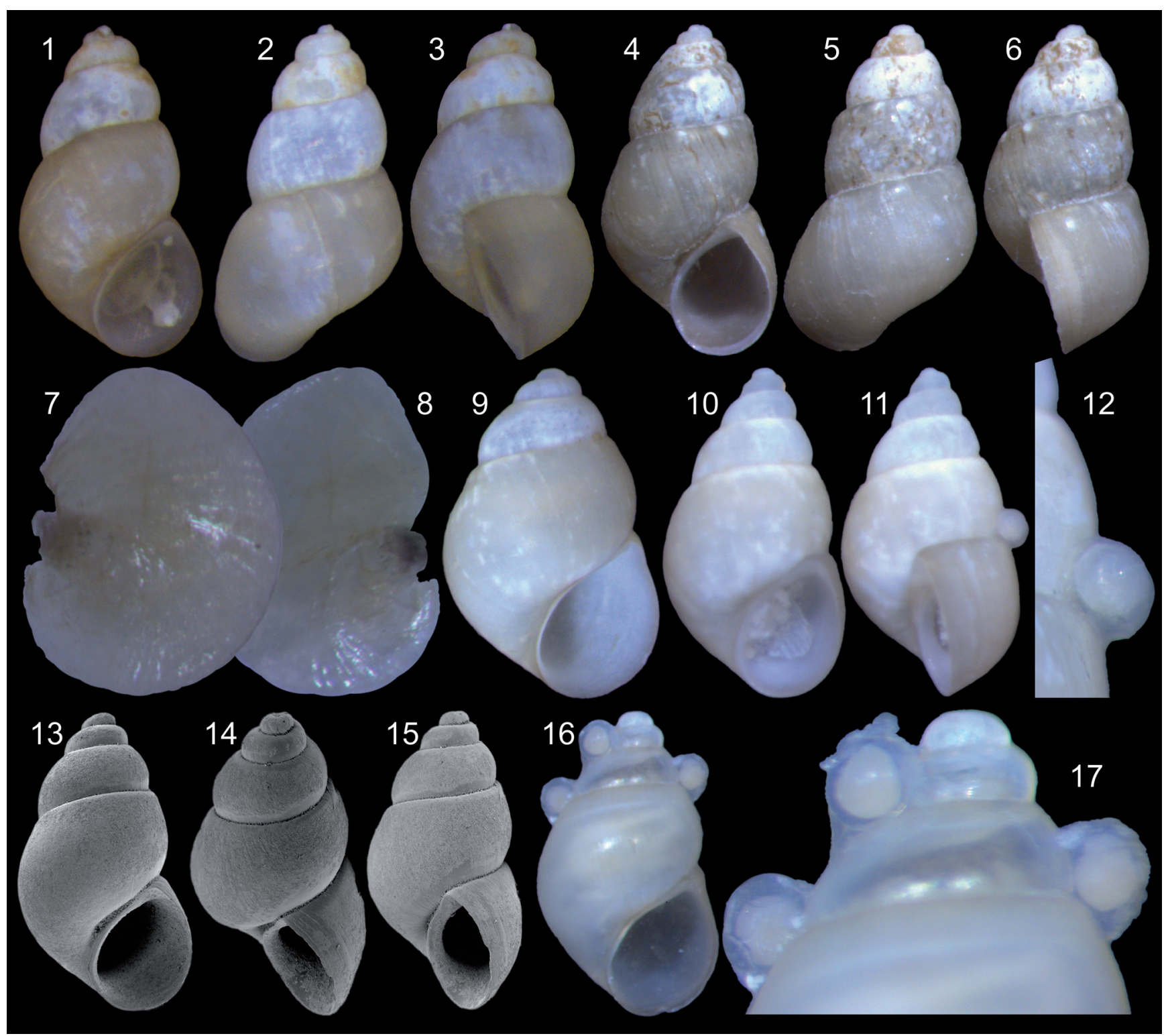

Figures 1-17. Heleobia brucutu sp. nov., hard parts: (1-12) paratypes MZSP 151289: (1-3) \#1, frontal, dorsal and right views (L 2.6 mm); (4-6) \#2, frontal, dorsal and right views (L $2.5 \mathrm{~mm}) ;(7-8)$ operculum, outer and inner views (L $0.7 \mathrm{~mm}) ;(9)$ \#3, frontal view (L $2 \mathrm{~mm}) ;(10-12)$ \#6, frontal, right view (L $2.7 \mathrm{~mm})$ and detail of egg capsule with young specimens inside; (13-15) holotype, SEM, frontal, right-slightly apical, right-slightly frontal views (L 2.7 mm); (16) paratype with 3 egg capsules attached, with embryo inside, frontal view ( $2.1 \mathrm{~mm})$; (17) same, detail of apical region.

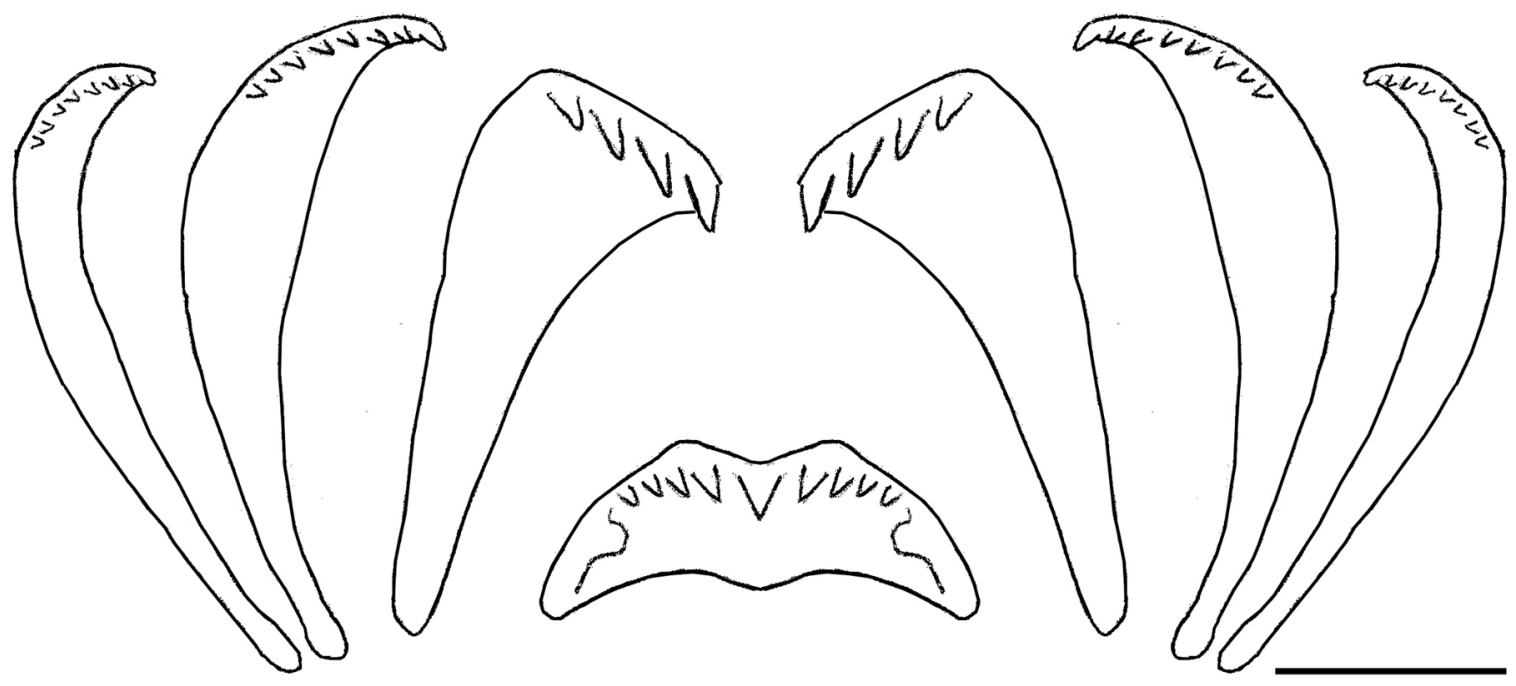

Figure 18. Heleobia brucutu sp. nov.: radula drawings. Scale bar $=100 \mu \mathrm{m}$. 
Distribution: Only known in the type locality.

Habitat and ecological notes: Heleobia brucutu sp. nov. has a very restrict distribution, so far known from a small stretch of the Pratinha stream, at the Pratinha lake, near the Pratinha cave entrance (Fig. 3). Details about the type locality were previously discussed by some authors (Lima \& Gerhard, 2001; Zanata et al., 2017). The Pratinha Lake have a maximum depth of around $1.5 \mathrm{~m}$ and possesses substrate composed mainly of sand, rocks and muddy. At this place empty shells and living individuals of $H$. brucutu sp. nov. composes small substrate patch-
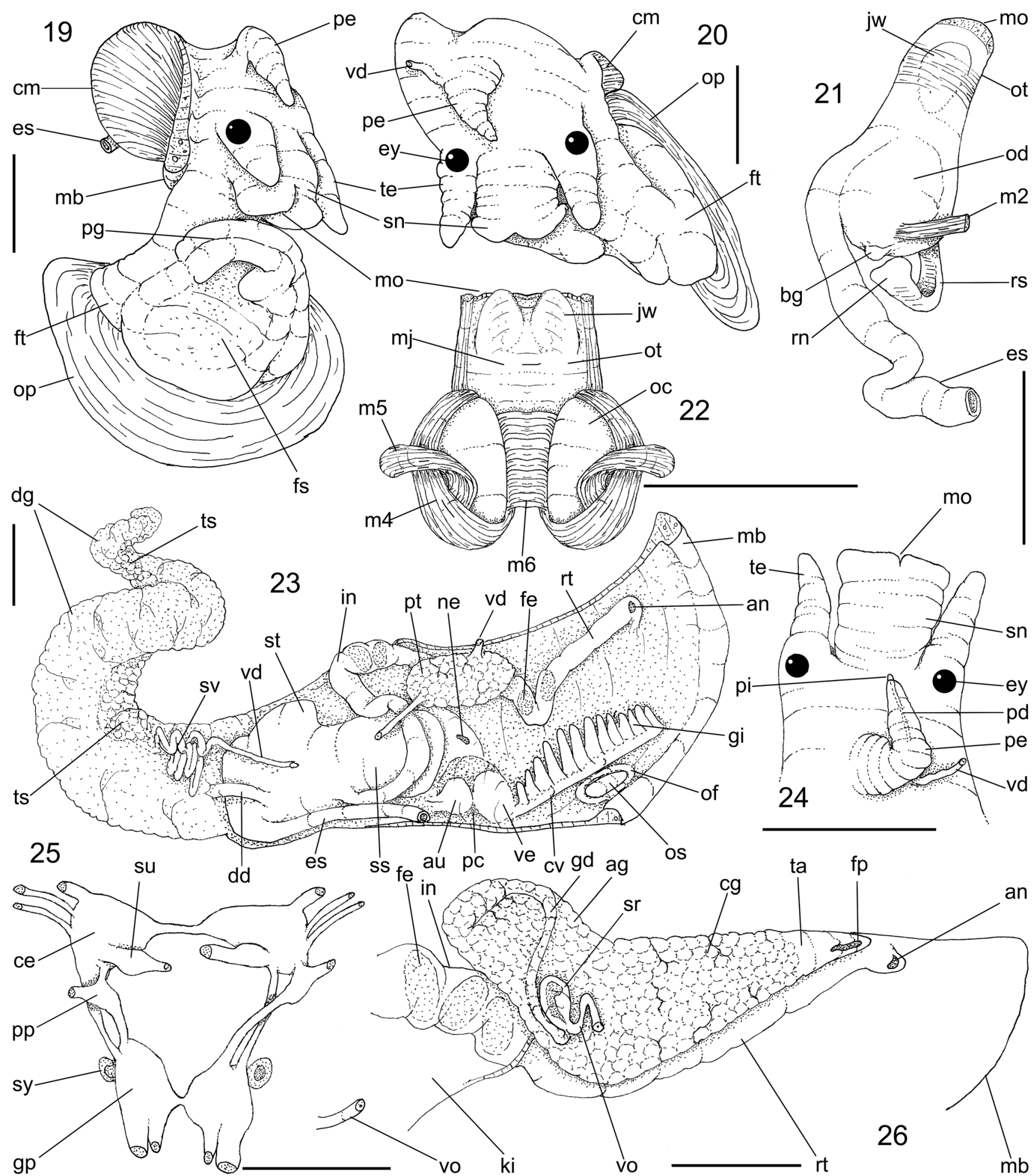

Figures 19-26. Heleobia brucutu sp. nov., anatomical drawings: (19) head-foot, male, right-slightly dorsal view; (20) same, dorsal view; (21) foregut, right view; (22) buccal mass, dissected, radula removed, odontophore deflected downwards, dorsal view, buccal hoof expanded upwards, ventral view; (23) pallial cavity hoof, ventral view, and visceral mass partially uncoiled, most structures as in situ, digestive gland portion ventral so stomach (st) removed, anterior region of visceral vas deferens (vd) sectioned; (24) head, male, focusing penis; (25) nerve ring, dorsal view; (26) pallial oviduct, ventral view, topology of some adjacent structures also shown. Scale bars $=0.25 \mathrm{~mm}$. 
es, mainly on the sandy bottomed portions of the substrate. The aquatic vegetation is composed mainly of Cabomba sp. The Pratinha Lake possesses high water transparence, with around $8 \mathrm{~m}$ of horizontal visibility (Lima \& Gerhard, 2001). Heleobia brucutu sp. nov. occurs syntopically with the bioinvader snail Melanoides tuberculatus (Müller 1774) (Oliveira et al., 2019). The new species is the main food resource of the Astyanax brucutu, the endemic and Critically Endangered durophagous "lambari" of the Pratinha river (Zanata et al., 2017).

Development: in some specimens ( 10\%), small spherical egg capsules were found attached to the shell (Figs. 11, 12). A small protoconch-bearing embryo was seen by translucence inside each capsule (Fig. 12).

Material examined: Types.

\section{DISCUSSION}

The minuteness of the shell, its slightly turriform shape, and the pallial oviduct arrangement justify the generic attribution of $H$. brucutu sp. nov. (Hershler \& Thompson, 1992). Smaller than $2.5 \mathrm{~mm}$, Heleobia brucutu sp. nov. is one of the smallest species in the genus (Simone, 2006a). The deep suture and rounded whorls profile approached it from few congener species that occur in Brazilian territory and neighborhood (Simone, 2006a), with which it needs to be compared. It differs from $\mathrm{H}$. bertoniana (Pilsbry, 1911), from H. cuzcoensis (Pilsbry, 1911), and from H. parchappei (d'Orbigny, 1835) in being smaller (the three are $\sim 6 \mathrm{~mm}$ long), in lacking a so acuminated spire, as the spire is somewhat dome-shaped, and presenting a narrower umbilicus. From H. manni (Baker, 1913) in being much narrower and with smaller peristome. From H. pusilla (Haas, 1949) in having a small beak at the apex and a more cylindrical outline. Heleobia brucutu sp. nov. also resembles Lyrodes peteningensis (Gould, 1852) and L. subgradatus (Haas, 1952), from which it differs in having shallower suture, more angled apex, and proportionally smaller peristome; however, it does not belong to Lyrodes in lacking expanding last whorl in the shell.

The reproductive strategy of attaching egg capsules in the shell also appears a distinctive character, as it has not been observed in other congener species. The laid egg capsules have their entire development attached in the shell, from embryo (Fig. 21) up to 2 whorls of shell (Fig. 12).

Anatomically, $H$. brucutu sp. nov. has the usual fashion of the family, including voluminous stomach and pallial genital structures, and penis with tubular duct (Simone, 2006b, 2011). A synopsis of the Brazilian brackish and freshwater rissooideans/trucatelloideans is found in Silva (2003), which, associated to other recent papers (e.g., Lydeard \& Cummings, 2019), bases the present discussion. The new species has a small gill, bearing only few filaments (Fig. 23: gi); the osphradium is proportionally large, and has a satellite fold which is not found in other species. Heleobia brucutu sp. nov. has an unusual penis structure if compared to other close species. It is relatively small, conic, and the terminal papilla is minute (Fig. 24: pi); additionally, the penis of the other Heleobia usually has glandular bulbs along it, which are absent in new species. The pallial oviduct usually has both, a seminal receptacle, and a bursa copulatrix, located close from each other in posterior region of the organ; however, $H$. brucutu sp. nov. has a single structure, tentatively called receptacle herein. On the other hand, a long tube immersed in the posterior region of the albumen gland (Fig. 26: gd) is an exclusivity. The small proportional size of the pleural ganglia at the nerve ring (Fig. 25: pp) looks also uncommon; they usually are the smallest ganglia, but those of the new species appear outstanding.

The South American non-marine rissooideans/trucatelloideans have usually proven to have a high level of endemicity, being sometimes endemic of a single cave (e.g., Simone \& Moracchioli, 1994; Simone, 2012), a small stretch of a river or from a lake (e.g., Simone \& Rolán, 2021). This appears also to be the case of $H$. brucutu sp. nov., which seems as endemic of the Pratinha lake, Iraquara, Bahia, as much as its fish predator (Zanata et al., 2017); efforts to collect the gastropod and its fish predator were not successful in other bodies of water from that region. Although the gastropod is relatively common in that lake, its high geographic restriction indicates a species that merits protection. Moreover, the characid fish appears to be specialized on only eating $H$. brucutu sp. nov. The known populations of both species (fish and gastropod) are entirely concentrated in a single locality which is subjected to several deleterious anthropogenic impacts (Zanata et al., 2017). Applicating the IUCN (2016) Red List Criteria, the species should be categorized as Critically Endangered (CR) according to its so far known restricted geographic distribution. For more details on the fish endangered attribution and habitat see Zanata et al. (2017).

\section{ACKNOWLEDGEMENTS}

Funding for field activities was provided by CNPq (grant \#476495/2010-5; \#562335/2010-2, junior author) and FAPESB (G.V.O grant \#310/2016). Mario C.C. de Pinna (MZSP) also kindly provided financial support that covered part of the expedition to Rio Pratinha. Permission for collecting was granted by IBAMA \#13754-1 and 10560-1.

\section{AUTHOR'S CONTRIBUTIONS}

L.R.L.S: taxonomical treatment, dissection, drawings, plates layout, and final completion. G.V.O.: collecting samples, SEM examination and images, ecological and environmental information.

\section{REFERENCES}

International Union for Conservation of Nature and Natural Resources (IUCN). 2016. Guidelines for using the IUCN Red List categories and criteria. Available: https:// www.iucnredlist.org/resources/redlistguidelines. Access: 04/04/2021. 
Hershler, R. \& Thompson, F.G. 1992. A review of the aquatic gastropod subfamily Cochliopinae (Prosobrancha: Hydrobiidae). Malacological Review, (suppl. 5): 1-140.

Kabat, A.R. \& Hershler, R. 1993. The prosobranch snail family Hydrobiidae (Gastropoda: Rissooidea): review of classification and supraspecific taxa. Smithsonian Contributions to Zoology, 547: 1-94.

Koch, E.; Martin, S.M. \& Ciocco, N.F. 2015. A molecular contribution to the controversial taxonomical status of some freshwater snails (Caenogastropoda: Rissooidea, Cochliopidae) from the Central Andes desert to Patagonia. Iheringia Serie Zoologia, 105(1): 69-75.

Lima, F.C.T. \& Gerhard, P. 2001. A new Hyphessobrycon (Characiformes: (haracidae) from Chapada Diamantina, Bahia, Brazil with notes on its natural history. Ichthyological Exploration of Freshwaters, 12(2): 105-114.

Lydeard, C. \& Cummings, K.S. 2019. Freshwater mollusks of the world: a distribution atlas. Baltimore, Johns Hopkins University Press. 256p.

Oliveira, S.R.; Neves, E.; Mariano, E.; Mugnai, R. \& Johnsson, R. 2019. A possible natural dispersal mechanism among juveniles of the bioinvader snail Melanoides tuberculata (Thiaridae: Gastropoda) by floatation. Journal of Conchology, 43(4): 337-343.

Silva, M.C.P. 2003. Hydrobiidae (Gastropoda, Neotaenioglossa, Rissooidea) da planície costeira do Rio Grande do Sul, Brasil. PhD Thesis. Porto Alegre, Universidade Federal do Rio Grande do Sul. 382p. Available: https://lume.ufrgs.br/bitstream/handle/10183/3446/000400850. pdf? sequence $=1$ \&isAllowed $=\mathrm{y}$.
Silva, M.C.P. \& Veitenheimer-M., I.L. 2004. Nova espécie de Heleobia (Rissooidea, Hydrobiidae) da planície costeira do sul do Brasil. Iheringia, Série Zoologia, 94(1): 89-94.

Simone, L.R.L. 2006a. Land and Freshwater Molluscs of Brazil. São Paulo, EGB/ FAPESP. 390p.

Simone, L.R.L. 2006b. Accounts on the phylogeny of the Rissooidea (= Hydrobioidea) and Littorinoidea, based on some American representatives, as base for a future taxonomic revaluation (Mollusca, Caenogastropoda). Strombus, 13(2): 18-26.

Simone, L.R.L. 2011. Phylogeny of the Caenogastropoda (Mollusca), based on comparative morphology. Arquivos de Zoologia, 42(4): 161-323.

Simone, L.R.L. 2012. A new genus and species of cavernicolous Pomatiopsidae (Mollusca, Caenogastropoda) in Bahia, Brazil. Papéis Avulsos de Zoologia, 52(40): 515-524.

Simone, L.R.L. \& Moracchioli, N. 1994; Hydrobiidae (Gastropoda: Hydrobioidea) from the Ribeira Valley, S.E. Brazil, with descriptions of two new cavernicolous species. Journal of Molluscan Studies, 60:445-459.

Simone, L.R.L. \& Rolán, E. 2021. A new genus and three new species of freshwater cochliopids (Caenogastropoda) from Goiás, Brazil. Iberus, 39(1): 1-21.

Zanata, A.M.; Lima, F.C.T.; Di Dario, F. \& Gerhard, P. 2017. A new remarkable and critically endangered species of Astyanax Baird \& Girard (Characiformes: Characidae) from Chapada Diamantina, Bahia, Brazil, with a discussion on durophagy in the Characiformes. Zootaxa, 4232(4): 491-510. 